Li Jin

\title{
When in China, do as the Chinese do? Learning compliment responding in a study abroad program
}

\begin{abstract}
Recent years have witnessed an increasing number of English-speaking students studying abroad in China. Whether these students can learn and reflect in their behaviors certain uniquely Chinese-style speech acts during their sojourn in China merits investigation. This paper reports on a case study investigating what and how four American university-level students developed knowledge and skills of compliment responding in Mandarin Chinese when they were participating in an 8-week intensive summer language program in Shanghai. Among the four participants, two were from a $2^{\text {nd }}$-year Mandarin Chinese class and two from a $3^{\text {rd }}$-year class. The qualitative data were collected from one pre-study questionnaire, weekly semi-structured interviews (a total of 6 for each participant), participants' weekly reflective blogs, and the researcher's observation of participants' social interaction with native speakers of Mandarin Chinese. The results showed that despite their similar academic, linguistic, and cultural background, each participant experienced a heterogeneous and dynamic developmental process and developed different awareness and skills of compliment responding in Mandarin Chinese throughout the study abroad program. The researcher discussed how each participant's agency and individual social interaction with native speakers of Mandarin Chinese as well as local Chinese residents' socialization efforts during the study abroad program intertwiningly shaped what and how the participants learned about Mandarin Chinese compliment responding strategies.
\end{abstract}

Keywords: study abroad, Mandarin Chinese compliment responding strategies, agency, socialization, social interaction

\section{Introduction}

"When in Rome, do as the Romans do" is an age-old maxim that has guided many people in their survival in a foreign culture. It is squarely reflected in the assumed goals of many contemporary American study abroad (SA) programs: to help our students develop necessary cultural knowledge and linguistic skills to understand 
the target culture and to easily fit in the target culture if at all possible. In the field of foreign language education (FLE), SA has been perceived as an ideal foreign language learning context which provides rich cultural and linguistic input as well as numerous interaction opportunities for language learners (Kinginger 2008). Researchers have discovered that students develop holistic life skills (Vande Berg 2004), gain intercultural sensitivity (e.g. Engle and Engle 2004, Paige, Cohen and Shively 2004), and demonstrate high-level linguistic outcomes, particularly fluency in formulaic language (e.g. Magnan and Back 2007) and approximation of certain native norms for sociolinguistic variation (Kinginger 2009) during a sojourn abroad. Students also believe SA enriches their personal experience that is lacking at the home institution (Van Hoof and Verbeeter 2005).

Among overwhelming research interest in students' psychological, cognitive, and linguistic development in a SA program is one line of research that aims to uncover whether and how participants of a SA program may develop pragmatic skills, a.k.a. sociolinguistic ability, the ability to use a language appropriately in various social contexts. This ability is reflected in performing various speech acts and largely stipulates a learner's ability to blend into the target culture (Kasper 2001, Kinginger and Farrell 2004). However, findings from this line of research yield inconclusive if not controversial information about student learning in a SA program. Concerned about the much more complex linguistic repertoire in a SA program in comparison with the explicitly and linearly structured textbooks students are familiar with, some researchers (e.g. Iino 2006) caution that participants may not be aware of native speakers' language varieties stemmed from the gender, age, social status differences. In other words, SA participants may be confused by the language varieties they are exposed to, thus fail to develop certain pragmatic skills. In adidtion, based on a review of previous studies on pragmatic development in a SA program, Kinginger and Farrell (2004) conclude that SA participants do not always perform certain speech acts as native speakers do even if they notice the native norms. Moreover, recent years' SA population data (Institute for International Education 2010) show that the majority of college-level SA participants are non-FL major students. Thus, their motives may not necessarily be focused on improving their target language proficiency and cultural knowledge (Kinginger 2008). This complex picture calls into question what pragmatic skills SA participants can and/or are willing to develop during a SA program, particularly in a short-term one, and whether and how they will eventually perform according to the native norms.

Mainland China has arose as an increasingly attractive SA site among American college students as a result of its recent years' economic boom. Despite a popular assumption about students' cultural gains during a sojourn in China, very few empirical studies have been conducted to investigate SA participants' 
academic and linguistic development in such a different culture that has been long perceived as inscrutable by many westerners. Little is still known whether participants plan or are ready to develop the skills they need to blend into the culture and how they acquire the skills. To fill this research gap, the current study was intended to explore a group of SA participants' development of compliment responding (CR) strategies ${ }^{1}$, a significant pragmatic skill widely perceived as uniquely Chinese-style (Chen 1993, Pan 2000) but constantly needed in a Chinese-speaking environment, during a short-term SA program. The focus of the study was to uncover and explain the influences that may affect American students' development of Chinese-style CR strategies that can define their Chineseness in various compliment-related social interactions.

\section{Literature review}

\subsection{Theoretical framework: Sociocultural Theory}

Sociocultural Theory (SCT), developed by Russian psychologist, L. V. Vygotsky (Vygotsky 1978), is a theory of mind development that recognizes the crucial role played by the relationship between the learner and his/her social cultural surroundings during his/her higher-order mental development. It has been widely adopted into the field of second language acquisition (SLA) in the past decade to explain how students acquire a second language (L2) in and outside a classroom setting (Lantolf and Thorne 2006). Deviated from the more dominant cognitivist theory (e.g. Long 1985) that posits a conduit metaphor of SLA process, SCTinspired researchers focus on learners' participation in social interactions such as collaboration with peers or obtaining scaffolding help from more advanced others (a native speaker or a teacher) as a means to become a participant in the target social contexts (Pavlenko and Lantolf 2000). Learners' participation is mediated constantly by various physical and psychological tools of which language is the primary one that controls and directs human behaviors and relates to the world. Thus, learning a L2 is a process of learning the tool which in turn mediates the learner's thoughts and behaviors as well as relationship with the world.

Two important SCT constructs are particularly relevant in this study. The first one is agency (van Lier 2008) which is learners' contextually dependent initiative or responsibility for learning. According to Lantolf and Pavlanko (2001), agency

1 CR strategies in this study refer to the strategies used to respond to compliments, e.g. 谢谢 (thank you), 哪里哪里 (no no), 真的吗 (really)? 
is not static, but dynamically co-constructed by the learner and his/her social cultural surroundings such as the relationship with others in the context, the tools mediating the social interaction, and even the historical background of the learner. The second construct is affordance, a.k.a. linguistic affordance in SLA (van Lier 2000), which is what linguistic information and linguistic developmentrelated assistance offered in the environment. SLA researchers (e.g. Allen 2010, van Lier 2004) stress that the emphasis is not placed on either the learner or the environment, but the relationship between the two. In other words, the L2 learning process mainly entails how learners implement or de-implement their agency dynamically through the linguistic affordances provided in the environment.

As for language learning in a SA environment, Kinginger (2004) specifically warns that "access to language is shaped not only by learners' own intentions, but also by those of the others with whom they interact - people who may view learners as embodiments of identities shaped by gender, race, and social class" (p. 221). In other words, assuming learners are highly motivated to initiate the learning, linguistic affordance in a SA program may not necessarily be sufficient or helpful for a language learner due to the ambiguous roles a SA participant plays in a target cultural community (Kinginger 2010). Thus, learners' self initiative and the linguistic affordance are two salient issues that merit future consideration when investigating language learning, or more specifically pragmatic development in a SA environment.

\subsection{Compliment responding in Chinese and American cultures}

As an important speech act constituting communicative competence of every member of a social community, compliment responding (CR) has been extensively studied in various fields such as sociolinguistics (e.g. Herbert 1986, 1990, Pomeranz 1984), pragmatics (e.g. Chen and Yang 2010, Wolfson 1983, Ye 1995, Yu 2004), and cross-cultural communication (e.g. Golato 2005). In the field of SLA, L2 pragmatics researchers (e.g. Hinkel 1996, Kasper and Schmitch 1996, Kasper 2001) have come to a general understanding that L2 learners may naturally resort to their L1 pragmalinguistic repertoires when they have to perform speech acts such as CR in unfamiliar L2 contexts or may not follow the L2 norms even if they know how native speakers perform certain speech acts. In order to understand how American learners of Chinese develop Chinese CR speech act norms, it is worth visiting the literature on CR in both Mandarin Chinese and American English.

Like many other speech acts, the research findings on CR present a complex, even controversial rather than unified picture about how native speakers of Chinese and English perform CR in various social contexts, particularly after taking 
into consideration the social status, gender, and age differences between the complimenter and the complimentee. Researchers (e.g. Chen 1993, Chen and Yang 2010, Spencer-Oatey and Ng 2002, Ye 1995, Yu 2004) agree that it is oversimplification to say that Chinese people automatically reject all compliments or that explicitly accepting compliments is considered impolite. The abundant CR research in mainland China yields the following general understanding: 1) compared to English speakers, Chinese people in general tend to deny compliments on performance such as 哪里哪里 nali nali (no, no), 不会吧? (It cannot be true), 还好了, 你过奖了 (It is all right. You are flattering me), but accept compliments on appearance particularly from friends and acquaintances such as 谢谢 (thank you), 那当然喽 (of course), 好开心啊 (I am so glad); 2) Chinese people also frequently use the deflecting/evading strategy that falls in the middle of acceptance and rejection, in other words, the complimentee neither accepts nor rejects a compliment, such as 喜欢的话, 送给你! (If you like, you can have it.), 是吗 ? (really?), 呵呵, 妈妈给我买的 (hehe, my mom bought it for me) when communicating with friends or acquaintances; 3 ) men tend to not accept compliment on appearance while women tend to accept it; 4) Some traditional denial formulas such as 哪里哪里, 不敢不敢 (no, no) may presuppose acceptance in certain context despite their negative forms; and 5) sometimes multiple strategies are used such as “谢谢，做得不好，瞎做” (Thank you. I didn’t do well. I am an amateur). Opposite to Mandarin Chinese, CR strategies in American English show a more homogenous and stable trait. Following Holme's (1988) seminal work on politeness maxims in social interactions, research on CR strategies used by American English speakers shows: 1) the unanimously accepted CR strategy in American English is "Thank you!" as the complimentee can agree with the speaker without serving too much self-praise; 2) compliments from men are generally accepted particularly by woman whereas those from women are most often unaccepted. Cross-cultural communication researchers (e.g. Chen 1993, Fong 1998) also believe that the difference in CR use between Mandarin Chinese and American English stems from different views toward compliment giving in respective culture. In general, Chinese compliment is meant to acknowledge performancerelated achievements (Ye 1995). Thus, if it comes from a senior or more powerful person, it is usually accepted as an evaluative judgment whereas a compliment from a peer is usually denigrated to show modesty. Compliments on objects and appearance from friends are considered as an attempt for solidarity, thus are usually accepted. By contrast, American compliment is intended to encourage or make other people feel good about themselves, and thus is usually accepted.

CR is one of the salient politeness behaviors in all cultures. Noting the nature of politeness strategies, Pan (2000) pinpoints that politeness behaviors are shaped by "deep-rooted beliefs concerning the perception of power relations, 
concept of self and other, and understanding of interpersonal relationships" (5). As power can be defined by a person's rank, age, gender, expertise, money, knowledge and so on, choosing appropriate politeness strategies in various social settings naturally entail a complex analysis of the power relation between an interlocutor and self. As discovered in previous studies, the politeness strategies in Chinese culture attend to the relational and hierarchical dimensions particularly among ingroup members whereas American culture observes egalitarianism and camaraderie. The formality of social contexts also influences politeness strategy use. For example, Kádár and Pan (2011) caution that self-deprecating behaviors such as 哪里哪里 usually occur in formal contexts rather than daily conversational contexts. The aforementioned research on CR strategies used by Mandarin Chinese and American English speakers in intracultural communication clearly illustrate that how power, social distance, complement themes and contexts shape the use of certain CR strategies culturally. This gap stipulates the difficulty American students from a camaraderie-valued culture may encounter when developing CR strategies in a hierarchy-and-context-bound culture.

\subsection{Politeness strategies in intercultural communication}

Pan (2000) elaborates that politeness and social etiquette are often observed and practiced in ingroup (including families, relatives, friends, fellow school mates and colleagues) interactions in Chinese culture. In particular, the powerless interactant observes the politeness more than the power holder. Outgroup members are considered temporary contacts that do not hold any long-term value in the social relationship, thus do not share face concern. Most foreigners traveling in China fall in the category of temporary residents or outsiders in a local community. They thus may not be treated with certain forms of politeness geared toward ingroup members such as holding no expectation for foreigners to act like a Chinese. On the other hand, Kádár (2011) also notes that some Chinese people tend to be more westernized as a result of China's economic development and more contact with western cultures. For instance, more people may adopt 谢谢 (thank you) when responding to a compliment, particularly from a stranger. In other words, American students' outgroup member identity may prevent them from accessing learning resources available to Chinese ingroup members.

In all, the review of literature on SCT and research on CR strategies in intracultural and intercultural communication in China and the U.S. provides a theoretical framework to interpret and analyze the discursive social cultural contexts American students studying abroad in Mainland may encounter. It is hoped that these constructs help decipher the unique learning process the learners may go 
through when developing Chinese CR strategies when studying abroad in mainland China.

\section{The study}

\subsection{The study context and participants}

The study was a part of a larger-scale study and was conducted in summer 2010 in an 8-week intensive language program (7 weeks of intensive formal language instruction in Shanghai and 1 week of group travel in Beijing). The program was organized by a private university in the Midwest of the U.S. and hosted by a prestigious university in Shanghai, China. A total of 12 students attended this summer study abroad program. Students enrolled in this program were required to have learned Chinese language for at least one year before going abroad. Before their departure, students were also required to take a cultural preparation course (a total of 21 hours of class contact time) to develop basic understanding of the cultural products and practices in modern China, such as the diversity of social and linguistic norms in various regions of modern China and how modern Chinese people view gender issues. After arriving to the Shanghai program which spanned from late June to early August 2010, students were divided into two classes: the $2^{\text {nd }}$-year class for students who had completed one year of Chinese learning in the U.S., and the $3^{\text {rd }}$-year class for those who had completed two years of Chinese. The textbooks used in both classes were in the same sequence as those used on the U.S. campus. From Monday through Thursday, each class met for three grammar sessions (45 minutes per session) in the morning taught by a professor from the host institution and two language practicum sessions in the afternoon taught by a graduate student from the host institution. Every weekday after all classroom-based sessions were finished, each student met with their individual tutors who were also graduate students from the host institution for one hour to practice speaking Chinese freely or discuss about cultural issues of their own interest. All the classroom-based instruction was finished by 3:10 pm every weekday. Students planned on their own activities in all weekday evenings and weekends. Since all students in this program stayed in a hotel building which is located in a commercial district at a 20 -minutes walking distance from the university campus, students had abundant exposure to the local community when they traveled between the campus and their hotel rooms, went shopping, eating and sought entertainment in their leisure time. 
The current study focused on the CR learning process of 4 participants among whom one was female, three male, two were in the $3^{\text {rd }}$-year class and 2 in the $2^{\text {nd }}$ year class, three (Anli, Siding, and Erkai) were Caucasian and one half-Asian-andhalf-Caucasian (Diwen). Except for Anli who briefly visited China on a two-week tour in her high school, all three other participants had never visited China before this study abroad program. Despite the fact that Diwen's mom was from a privileged Chinese family, he was born in the U.S. and exposed to minimum Chinese culture during his upbringing. The detailed information about the four participants is included in Table 1.

\begin{tabular}{|c|c|c|c|c|}
\hline & Anli & Erkai & Siding & Diwen \\
\hline Gender & Female & Male & Male & Male \\
\hline Age & 20 & 21 & 21 & 20 \\
\hline Ethnicity & Caucasian & Caucasian & Caucasian & $\begin{array}{c}50 \% \text { Caucasian } \\
50 \% \text { Asian }\end{array}$ \\
\hline $\begin{array}{l}\text { Language } \\
\text { Level }\end{array}$ & $3^{\text {rd }}$-year Chinese & $3^{\text {rd }}$-year Chinese & $2^{\text {nd }}$-year Chinese & $2^{\text {nd }}$-year Chinese \\
\hline Major & Chinese Studies & & & \\
\hline $\begin{array}{l}\text { Prior } \\
\text { language } \\
\text { and culture } \\
\text { exposure }\end{array}$ & $\begin{array}{l}\text { - College-level } \\
\text { classroom } \\
\text { instruction } \\
\text { in the U.S.; } \\
\text { - one-week tour } \\
\text { in China } 3 \\
\text { years ago }\end{array}$ & $\begin{array}{l}\text { - College-level } \\
\text { classroom } \\
\text { instruction } \\
\text { in the U.S.; } \\
\text { - Never traveled } \\
\text { to China }\end{array}$ & $\begin{array}{l}\text { - College-level } \\
\text { classroom } \\
\text { instruction } \\
\text { in the U.S.; } \\
\text { - Never traveled } \\
\text { to China }\end{array}$ & $\begin{array}{l}\text { - College-level classroom } \\
\text { instruction in the U.S.; } \\
\text { - Potty language and } \\
\text { culture exposure from } \\
\text { mom; } \\
\text { - Never travelled to } \\
\text { China }\end{array}$ \\
\hline $\begin{array}{l}\text { Prior } \\
\text { knowledge } \\
\text { about CR } \\
\text { in China }\end{array}$ & $\begin{array}{l}\text { To be modest } \\
\text { e.g. 哪里哪里 } \\
\text { 还好 }\end{array}$ & $\begin{array}{l}\text { To be modest } \\
\text { e.g. 哪里哪里 } \\
\text { 还好 }\end{array}$ & $\begin{array}{l}\text { To be modest } \\
\text { e.g. 哪里哪里 }\end{array}$ & $\begin{array}{l}\text { To be modest } \\
\text { e.g. 哪里哪里 }\end{array}$ \\
\hline $\begin{array}{l}\text { Purpose } \\
\text { in the } \\
\text { program }\end{array}$ & $\begin{array}{l}\text { - To improve } \\
\text { language } \\
\text { proficiency; } \\
\text { - enhance the } \\
\text { understanding } \\
\text { of the culture }\end{array}$ & $\begin{array}{l}\text { - To improve } \\
\text { language } \\
\text { proficiency; } \\
\text { - To understand } \\
\text { the society in } \\
\text { general to be } \\
\text { a successful } \\
\text { businessman }\end{array}$ & $\begin{array}{l}\text { - To improve } \\
\text { language } \\
\text { proficiency; } \\
\text { - To understand } \\
\text { the society in } \\
\text { general to be a } \\
\text { successful } \\
\text { businessman }\end{array}$ & $\begin{array}{l}\text { - To improve language } \\
\text { proficiency; } \\
\text { - To understand the } \\
\text { culture as a half Asian } \\
\text { and to be a successful } \\
\text { businessman }\end{array}$ \\
\hline
\end{tabular}

Table 1: Participants 
The four participants were focused on in this study for two major reasons: 1) 4 was a manageable number of participants from whom the researcher could collect in-depth data during a period of 8 weeks; and 2) based on the background information survey, the four participants well represented four common types of CSL learners in a study abroad program because of their prior social, cultural, historical, and linguistic experiences in both the U.S., and China. At the beginning of the program, all participants reported that their goals in this SA program were to improve their Chinese language skills and cultural understanding. Among the four, Anli was the only student majoring in Chinese studies. She was extremely driven to enhance her Chinese, including adopting the culturally acceptable behaviors "to talk like a Chinese, if that is possible at all" (interview with Anli on 7/1/2010). The other three participants were all majoring in business-related areas. Toward the beginning of the program, both Siding and Diwen explicitly expressed their goal in this program is to "fit in. to do it as the Chinese do it." (interview with Siding on 7/1/2010) or to "blend in more" (interview with Diwen on $7 / 7 / 2010$ ). By contrast, Erkai held a more utilitarian attitude toward learning Chinese as shown in the pre-study survey (Table 1) and in an interview transcript "I just feel like the culture that I live in is different, so I may not adopt a Chinese way that makes me uncomfortable" (interview with Erkai on 7/7/2010).

The current study was intended to answer two research questions:

1. What CR strategies did American learners of Chinese develop during an 8-week SA program?

2. How did American learners of Chinese develop CR strategies during the SA program?

To answer the questions, a case study approach (Berg 2004, Stake, 1995) was adopted to unfold with in-depth detail the CR developmental process each learner experienced in a complex SA context.

\subsection{Data collection}

Prior to the study abroad trip, voluntary participants were recruited and informed of what they were expected to do for the study during the study abroad program. To reduce the researcher's effect on data collection, all participants were instructed that the study was solely for the researcher's academic interest and none of the information they would share with the researcher would be used against their academic performances in the program and pseudonyms would be used to protect their identities. As a return of favor, the researcher offered to provide tutoring and interpretation service to participants throughout the program. Both 
quantitative and qualitative data were collected from four data sources to ensure data triangulation (Lincoln and Guba 1985).

First, a pre-study survey (Appendix A) was administrated prior to participants' participation in the study abroad program. The survey helped solicit information about each participant's gender, age, prior experience with learning Chinese language and exposure to Chinese culture, prior knowledge and skills about CR such as how Chinese people respond to compliments and why Chinese people respond to compliment in certain ways, and their purpose of participating in the SA program. Information collected from the survey helped the researcher understand each participant's social, cultural, historical, and cognitive situations that might shape their agency in this program.

Second, a weekly formal semi-structured interview (see Appendix B for a list of sample interview questions) was conducted with each participant to help them recollect what new CR strategies were acquired in the past one week and how they acquired the strategies. Participants were also asked to estimate how frequently they were engaged in compliment-related conversations. Additional individualized questions were asked based on each participant's unique experience and perception of their pragmatic learning such as why a participant thought the compliments he received from Chinese people were not sincere. This method was the primary data source to analyze what each participant developed the pragmatic competence because SA participants may not perform according to the native norms even if they notice the norms, which deems observation as an ineffective method for understanding the learning outcomes, as suggested by Kinginger and Farrell (2004). All interviews were conducted in English on a Tuesday or Wednesday evening after participants' daily study at school either in each participant's hotel room or at a quiet place in the hotel. Each interview lasted for 15 30 minutes depending on each participant's weekly experience and the amount of information he/she could remember. All interviews were audiorecorded and later transcribed by a native English external transcriber. Due to the various changes students needed to cope with after their arrival to Shanghai in the $1^{\text {st }}$ week and after their arrival to Beijing in the $8^{\text {th }}$ week, the first interview for each participant was conducted at the beginning of the $2^{\text {nd }}$ week and the last interview was in the middle of the $8^{\text {th }}$ week. A total of 6 interviews for each participant were conducted throughout the SA program.

The $3^{\text {rd }}$ source of data was participants' weekly reflective blog entry. As each student in the program was required to keep a weekly reflective blog on the class website to reflect on their linguistic and cultural learning throughout the program, information from each participant's weekly blog entries that were pertinent to their CR development were gleaned by the researcher to supplement and triangulate the data collected through the interviews. 
The $4^{\text {th }}$ source of data was the researcher's observations and reflective journals to provide direct account of participants' CR speech act in natural social settings that supplemented and further triangulated data collected from the other two sources. Each Tuesday, the researcher conducted roughly 4 hours of formal classroom observations, 2 hours in each class. Occasional classroom observations on other weekdays were also conducted. During the classroom observations, the researcher took notes of scenarios in which each participant exchanged or explicitly inquired about CR strategies with their classmates, instructor and TA. Observations during all group outings and field trips were conducted more incidentally.

\subsection{Data analysis}

Once the pre-study survey results were collected, all information from the survey was compiled as shown in Table 1 to assist the following data analysis. Data from the interviews, participants' reflective blogs and the researcher's reflective journals was analyzed at two major phases: within-case analysis and cross-case analysis (Yin 2003). Each participant was considered a case. Constant comparison method (Lincoln and Guba 1985) and matrix display (Miles and Huberman 1995) were employed to first organize and decipher data from each case, then to compare and contrast data from all four cases. At the within-case analysis phase, data were preliminarily analyzed each week as soon as any new entry of data was collected from each participant. Within-case analysis was conducted generally in five steps. In step 1, the researcher reviewed one participant's interview transcript to have a general view of what CR strategies the participant acquired and under what circumstance he or she acquired the strategies. In step 2, relevant raw data were grouped under recurring themes in terms of the types of CR strategies and the circumstances under which the CR strategies were acquired. Constant comparison method was used to avoid redundant themes and mislabeled themes. In step 3, CR-related information from the participant's weekly reflective blog and the researcher's reflective journals were examined for any additional theme that was missing in the interview transcript, but could address the research questions. A scheme for each recurring theme was created in step 4. The recurring themes that emerged from data analysis for each participant were organized in a CRdevelopment matrix (see Appendix D). The same within-case analysis procedures were followed each week when a new set of data were collected. All data were recorded in the CR-development matrix. Finally, in step 5, after all of the information was compiled, a diachronic analysis was conducted to unpack how various environmental influences affected each participant's CR learning chronologically 
throughout the program. The same steps were repeated to analyze the data collected from other 3 participants. The scheme in the first within-case analysis was used to guide the data analysis in the other 3 cases. At the cross-case analysis phase, a synchronic analysis was conducted to compare and contrast each participant's CR developmental process and identify the differences and similarities in terms of how each participant dealt with their respective social interaction in order to acquire culturally acceptable CR strategies each week during the program.

\section{Findings}

\subsection{What CR strategies did participants learn during the program?}

Table 1 shows that before participants attended the program, from their prior class instruction, they all were familiar with one CR strategy in Chinese: “哪里 哪里 (no, no)”, which they learned directly from their textbook and believed was the standard Chinese way, similar to "thank you" in American English. Throughout the program, all participants developed a larger repertoire of CR strategies, mainly in four categories: “哪里哪里 (no, no)”, “谢谢 (thank you)”, other mitigating and deflective verbal strategies that fall between rejection and acceptance strategies such as 我的爸爸也很高 (my dad is also tall), and non-verbal strategies (smile, to laugh it off, to look away, hand gesture, etc) that can be used for various social functions as shown in Appendix C.

Anli. In week 1, Anli noticed that besides 哪里哪里, Chinese people also used “谢谢 (thank you)” as a CR, just like in English. In week 2, she learned from an American friend who was a veteran learner of Chinese and lived in China for years that deflecting a compliment by saying "you are better than I anyway" can "avoid any awkward transitions that may follow a compliment, such as attempting to think of an irrelevant return complement, or ending with a quick 'thank you' "' (Anli's $2^{\text {nd }}$ reflective blog). In week 4, after receiving excessive compliments on her physical features and Chinese language skills, Anli realized that Chinese compliments toward foreigners might serve non-politeness functions. She decided to brush it off by saying nothing or just smiling back, or to say “哪里哪里 (no, no)" to end the conversation when the compliment was on her appearance whereas to respond with "Well my speaking is ok but my listening comprehension is awful' or 'I write characters horribly' or something like that" when the compliment was 
on her Chinese skills to continue the conversation (interview with Anli on 7/20/2010). This resonates with her behavior observed by the researcher (as shown below). In the following conversation, Anli was observed to have used not only one verbal strategy but also body language during her interaction with her language professor at the beginning of one morning class:

\section{Observation Excerpt 1:}

Professor (a woman in her early 30s): 安丽, 你今天穿的裙子很好看啊。 (Anli, the skirt you wear today is really pretty.)

Anli: (smiling back and slightly lowering head) 哪里哪里 (no, no).

In week 5, Anli developed a new understanding of CR in Chinese: "people would be more likely to say 哪里哪里 (no, no) when they receive compliment on personal quality like intelligence or physical appearance” and “谢谢 (thank you) may be more appropriate if they receive compliment on tangible things, like shoes" (interview with Anli on 7/28/2010). However, toward the end of the program, Anli concluded that 哪里哪里 (no, no) was “just another way to say 谢谢 (thank you)", thus it was still "less modest than just not saying anything and just sort speaking with your own sort of facial expressions or just sort of brushing it off” (interview with Anli on 8/13/2010).

Erkai. In the first two weeks of the program, in addition to his consistent understanding that saying 哪里哪里 (no, no) was the standard Chinese CR strategy and 谢谢 (thank you) was an American way, Erkai also noticed that Chinese people usually laughed off or smiled in a shy way when receiving a compliment. However, he insisted on using 谢谢 (thank you) when people complimented on his language skills because "I grew up in American culture so I am used to saying 谢谢 (thank you). I am more comfortable with it" (interview with Erkai on 7/7/2010). In week 4, both the interview transcript and the researcher's observation reflection show that Erkai constantly used 谢谢 (thank you) to respond to any compliment he received because he realized Chinese compliment on his Chinese language skill was meant to encourage his learning. He also noticed that “maybe people say 谢谢 (thank you) and 哪里哪里 (no, no) - I guess depending on the situation" (interview with Erkai on 7/21/2010) although he was not sure in what context 哪里哪里 (no, no) or 谢谢 (thank you) is more appropriate. Toward the end of the program, Erkai came to a totally different understanding about the appropriateness of 哪里哪里 (no, no). “I've actually found that 谢谢 (thank you) is like more suitable than 哪里哪里 (no, no) because whenever I say 哪里哪里 (no, no) they like laugh” (interview with Erkai on 8/13/2010). Thus he concluded that “谢谢 (thank you) is a more appropriate CR strategy in China”. 
Siding. Because of his striking western looks and height, Siding had been flooded with various compliments on his appearance and language skills throughout the study abroad program. At the beginning of the program, cultivated with the knowledge that 哪里哪里 (no, no) was the standard modest way to respond to compliments in Chinese and driven by a desire to "desperately blend into the culture”, Siding “usually used 哪里哪里 (no, no)” whenever he received compliments (interview with Siding on 7/1/2010). However, he also observed that "sometimes people seem to be disappointed when I respond with 哪里哪里 when they compliment on my looks and Chinese" (interview with Siding on 7/13/2010). The researcher's observation reflection also shows that "Whenever the group went out, people, usually other tourists and street vendors, often singled out Siding and showered him with comments on his physical features. Siding usually responded with 哪里哪里 (no, no) with a genuine smile on his face” (the researcher's reflection journal on 7/10/2010). In week 4, Siding realized that 哪里哪里 (no, no) was "not natural but it is something that we have learned. It is just easy and comfortable to use" (interview with Siding on 7/21/2010) because whenever he used 哪里哪里 (no, no), some people gave awkward reaction. Instead, he found it was better received "to refuse it or to push the compliment to someone else, such as '噢, 谢谢你, 我妈妈的眼睛是绿色的 (oh, thank you. I got my green eyes from my mother)' or ‘哪里哪里, 我的爸爸也很高 (no, no, my dad is tall too)'” (interview with Siding on 7/28/2010) ${ }^{2}$ although he felt his Chinese was not good enough to say everything accurately and fluently. The researcher also observed that "after realizing some people used compliments to open a conversation with him, he chose to just respond casually with '谢谢 (thank you)' to avoid further communication as documented in the following observation excerpt:

\section{Observation Excerpt 2:}

(On a tourist site in a city nearby Shanghai)

Tourist (an older Chinese man): (standing beside Siding, smiling) 长得真高! (you are really tall!)

Siding: 谢谢 (thank you). (smiling back and walked away)” (the researcher's reflection journal on $7 / 25 / 2010$ )

Toward the end of the program, Siding concluded that "I usually push the compliment to someone else. I think it is definitely the way Chinese people use. And I can say it very fluently, compared to when I just arrived to China. But I am

2 Siding was using mixed strategies as Chinese people do. But the "pushing to other people" strategy is usually used by native speakers of Chinese to respond to compliments on objects (Ye 1995). 
still not sure when I could use 哪里哪里 (no, no) solely” (interview with Siding on 8/13/2010).

Diwen. In the first three weeks in the program, Diwen felt that the traditional Chinese way to respond to compliments should be 哪里哪里 (no, no) although Shanghai people started to use 谢谢 (thank you) as a result of the westernization. “But I always use 哪里哪里 (no, no) because I want to be like a Chinese. People seemed ok with my response." (interview with Diwen on 7/13/2010). He also noticed that "Chinese people also tend to look away or smile back shyly, or sometimes use a hand gesture" which indicates rejection of the compliment. The researcher's observation journal also confirmed that "Diwen seems to have quickly adopted the Chinese body language when responding to compliments. As shown in the following excerpt:

Observation Excerpt 3:

(At a local restaurant, Diwen helped a few students on the group order dishes on the Chinese menu. At the end of the dish-ordering:)

Waitress (a young woman in her mid 20s): 你的中文很好啊。(Your Chinese is very good)

Diwen: (looking away and smiling) 哪里哪里 (no no).

(Waitress smiled and continued collecting orders.) " (The researcher's reflective journal on $7 / 10 / 2010$ )

In week 4, Diwen reflected that a Chinese CR should "be as modest as possible. Deflect it - don't ignore it though. Definitely acknowledge it and don't just turn your head away - say 哪里哪里 (no. no) or 谢谢 (thank you) and then say it is not true or something. I mean basically any way to deflect a compliment is a good thing in Chinese" (interview with Diwen on 7/21/2010). The researcher's observation journal confirmed that "Diwen has adopted more body language when responding to compliments as shown in the following excerpt:

\section{Observation Excerpt 4:}

(In a morning class, after Diwen answered a question)

Professor (a middle-aged Chinese man): 苏棣文，你的发音很清楚 (Diwen, your pronunciation is very clear).

Diwen: (waving his right hand and smiling) 哪里哪里 (no no).”

(Professor smiled and continued teaching.) (The researcher's reflective journal on $7 / 23 / 2010$ )

Toward the end of the program, Diwen confirmed his understanding that “Chinese people are very modest so they wouldn't show their happiness when 
being complimented. They usually just deflected it in various ways." (interview with Diwen on 8/13/2010).

As shown above, all four participants understood that modesty is valued in Chinese culture as they agreed in the pre-program survey. Except for Erkai, all other three participants explicitly expressed the willingness as well as tried to act like a Chinese by adopting a modest CR strategy during their sojourn in China. However, at the end of the program, they showed extensive variations regarding their understanding of 1) what verbal and non-verbal CR strategies Chinese people often use and 2) in what context different strategies should be used. In terms of the types of CR strategies, Anli and Siding observed that non-acceptance-nonrejection deflective strategies are more often used. Erkai only observed the use of 谢谢 (thank you) whereas Diwen reported that Chinese people also use a certain hand gesture to deflect a compliment. In terms of the contexts where different CR strategies should be used, Anli thought 哪里哪里 (no, no) and 谢谢 (thank you) were equally less modest than a deflecting sentence while Erkai thought 哪里 哪里 (no, no) was outdated and 谢谢 (thank you) was a norm. Siding concluded that mitigating and deflecting strategies were more commonly used and 哪里哪里 (no, no) was rarely used. Diwen noticed his 哪里哪里 (no, no) was as well accepted as a hand gesture. In addition, participants such as Anli and Siding received so many compliments on their language proficiency and looks that they started to feel some compliments were not sincere and served alternative functions rather than exerting politeness. They thus developed relevant strategies to respond to these quasi-compliments.

\subsection{How did participants develop the CR strategies during the program?}

As illustrated in the interview transcripts, participants' blog entries, and the researcher's reflective journals, each participant experienced a very dynamic, discursive, and heterogeneous process to understand how to use various CR strategies in Chinese-speaking contexts. Three recurring themes, as shown in Appendix D, emerged to unfold each participant's CR learning process during the 8 weeks in the SA program: 1) frequency of compliment-related direct interactions with native speakers of Chinese each week, 2) the interactant(s) with whom they exchanged CR, and 3) learning venues through which they were engaged in learning CR strategies.

The data in Appendix D show that participants were engaged in unequal amount of compliment-related interactions each week throughout the program. 
Both Anli and Siding reported averagely 11 20 times/week of complimentrelated direct interaction with native speakers. When they had a strict schedule in regular weeks, there were not much compliment-related encounters. During the program field trips in Weeks 3 and 8, they generally were engaged in more than 20 times of compliment-related interactions with native Chinese. Erkai unfortunately was only engaged in a handful of compliment-related interactions each week. In week 6, he didn't even have any compliment-related encounter. Diwen reported that he had very few complimented-related interactions when he just arrived to Shanghai. Holding a belief that complimenting is a smart way to get better service or open a conversation with local residents, Diwen constantly complimented the people he encountered everyday, which exposed him to a great number of CR input. Toward the end of the program, he reported more than 20 times of compliment-related encounters each week. Because of his efforts in practicing his spoken Chinese during the program, Diwen was showered with compliments on his Chinese skills in the final week in Beijing because "Beijing is considered the cultural center, the wenhua zhongxin - you know if you try to speak the language with all the r's and stuff I think that makes them happy because they are like, 'Oh he's actually trying'" (interview with Diwen on 8/13/2010), which obviously provided abundant opportunities for him to try out his CR strategies.

Regarding the interactants with whom each participant had complimentrelated interactions, Anli, Siding, and Diwen reported that street vendors and local residents were the primary people with whom they had compliment-related interactions. In addition to the people in their daily life, Anli and Siding also reported that other Chinese tourists complimented on their looks and their language skills whenever they spoke Chinese in and outside Shanghai. Compared to the other three participants, Erkai rarely received compliments from local vendors and Chinese residents throughout the program. All participants also reported they had very occasional compliment-related interactions with their respective tutor and class instructors. In other words, the vast majority of complimentrelated interactions in which participants were engaged took place with native Chinese strangers.

Due to the fact that most CR-related learning took place outside class and each participant had individualized experience with native Chinese, their understanding of what and how to use CR strategies (e.g. when and how to 哪里哪里, 谢谢) in different contexts were constantly reshaped by their personal experience. They relied on two primary venues to develop CR strategies: 1) to observe native Chinese's reaction to CR strategies used by participants, and 2) to observe native Chinese's CR use. As for the first learning venue, namely, Anli and Siding received an excessive amount of compliments. Thus, they had numerous 
opportunities to test out their CR strategies. For example, at a massage shop, Siding observed that “I said that 哪里哪里 and she (masseuse) said 'Oh!' like she was disappointed.” (interview with Siding on 7/1/2010). After consistent negative feedback from native speakers, Siding eventually concluded that "it is not natural but it is something that we have learned - so it is us exercising what we have learned" (interview with Siding on 7/14/2010). Similarly, Anli constantly checked in what context 哪里哪里 was more acceptable. After various experiences, she decided that 哪里哪里 was not more modest than other deflective verbal or nonverbal strategies. In terms of the second venue, participants such as Erkai and Diwen rarely received compliments from native Chinese, particularly outside the school setting. Thus they mainly observed how native Chinese responded when they gave compliments for certain social purposes. For example, Erkai observed that his tutor was shy and just smiled when receiving compliments from him. He decided that “I am more comfortable with American way to say 谢谢” (interview with Erkai on 7/14/2010). After being laughed at by a street vendor when he used 哪里哪里, he concluded that 哪里哪里 was outdated and 谢谢 was more commonly used. As for Diwen, he intentionally joined various verbal interactions with native Chinese as he reported "I try to compliment on people's food and service. So they can talk to me.” (interview with Diwen, 8/1/2010). Through his proactive efforts, Diwen noticed that many Chinese deflected with hand gestures or by looking away when receiving compliments from him. Interestingly, among the four participants, only Anli reported toward the end of the program that she overheard a compliment-related conversation between her tutor and her friend, the first native-native conversation involving compliment exchanges she ever caught. Throughout the program, participants confessed they weren't able to catch native Chinese's conversations if they were not involved because either "I mean, usually I try to listen to people to try to pick up what they are saying in Chinese but I just get lost because it is so fast” (interview with Erkai on 7/1/2010) or “the Chinese aren't very quick to hand out compliments. It's not like in America where we, especially American students, are of the mentality that everyone needs to be complimented and validated" (interview with Diwen on 7/21/2010).

In sum, although all participants started the program with similar understanding about Chinese CR use, they continuously revisited and reshuffled their acquired knowledge and understanding about what CR strategies to use in various settings based on their individual compliment-related interactions with native speakers of Chinese. In other words, each participant's CR development varied according to the frequency of compliment-related interactions, the interactants, compliment content, and feedback given by native interactants they experienced during the program. 


\section{Discussion}

Although the study only focused on four participants, the findings show that each participant developed different repertoires of Chinese CR strategies and diverse understandings of the social contexts where CR strategies should be used. It is interesting to have a closer look at what caused the highly individual learning outcomes and process.

The first aspect that is worth special attention is the linguistic affordance (van Lier 2004) provided in the study abroad environment. Research (e.g. Chen 1993, Chen and Yang 2010, Kádár and Pan 2011, Spencer-Oatey and Ng 2002, Ye 1995, Yu 2004) on CR strategies in Chinese intracultural communication shows that CR strategy use is stipulated by the power relation (gender, age, social status), social distance, context, and compliment themes between two interactants. The politeness is often observed with ingroup members such as family, friends, relatives, colleagues, etc (Pan 2000). In intercultural communication, Chinese people may be westernized such as the extensive use of 谢谢 to accept all compliments or the vendor's laughing at Erkai's use of 哪里哪里. During the SA program, the participants were exposed to very limited contexts where CR strategies were used due to their foreign identity, the format of the SA program, and a relatively short sojourn in China. Namely, all 4 participants were not able to establish a solid and close connection with their professors, tutors, and other native Chinese peers. Hence, most of their compliment-related conversations took place with strangers on the streets where politeness is rarely observed in Chinese intracultural communication. When interacting with the strangers, the participants seemed to be constantly treated as outgroup members in terms of the amount and types of compliments given to them. For example, the excessive and direct compliments from strangers on language proficiency and physical features are rarely exchanged in pubic among native Chinese, particularly between opposite-gender strangers. Anli and Siding eventually discovered that many compliments were meant to merely open a conversation with them. In addition, the rare exchange of compliments among Chinese people also limited participants' observation of this speech act in an intracultural communication context. Hence, the study abroad environment did not seem to provide very helpful linguistic and relational affordance for the participants to observe how various social cultural factors influence Chinese CR strategy use (Iina 2006).

However, as the findings show, participants such as Anli, Siding, and Diwen still developed rather impressive skills and knowledge about Chinese CR strategies, which could be attributed to participants' agency. As van Lier (2004) claims that L2 learners' agency is dynamic and co-constructed by their own intention and their social cultural surroundings, each participant in this study manifested 
their agency quite dynamically, mediated by both internal and external influences. Among the 4 participants, Anli, Siding, and Diwen expressed strong desire to learn the Chinese way to speak at the beginning of the program whereas Erkai expressed a rather lukewarm utilitarian attitude toward learning Chinese in the program. During the program, Anli and Siding took advantage of the special attention they received from native Chinese and actively tested and reflected on the correct use of different CR strategies. Although they both realized some compliments were given as special treatments to foreigners, they developed strategies to respond to these quasi-compliments. By contrast, Erkai and Diwen received much fewer compliments due to their relatively less-celebrity looks, which put them at a disadvantage position in terms of the opportunities to test out various CR strategies. However, Diwen and Erkai executed opposite agency. Erkai was less driven to explore, not to mention perform various CR strategies like a native Chinese (Kinginger and Farrell 2004) particularly after he found out his tutor's shy smile was not his style. As for Diwen, determined to know more about his heritage as well as to be a more competitive business man in the future international market, he read broadly and reflected about Chinese culture and history before and during the SA program and proactively sought various opportunities to interact with native Chinese. As an extremely driven, observant and thoughtful language learner, Diwen developed very impressive skills and knowledge about CR strategies in China. It is not very difficult to predict that Diwen might have done less if he didn't want to discover more about his mom's heritage and that Erkai might have taken more efforts if he were as popular as Siding.

In all, this study investigated what CR strategies four participants in a SA context developed and how they developed those strategies which are often not explicitly taught in classrooms. As shown in this study, each participant's developmental process was shaped by the linguistic affordance provided in the SA context as well as his/her agency. On the one hand, the age, gender, social status, and education backgrounds of the Chinese native speakers with whom the SA participants interacted everyday were unpredictable. Their relatively short sojourn in China also prevented them from building close, meaningful, and diverse social connections in the local community. Thus, the quality and quantity of linguistic affordance may not be consistent and sufficient. Consequently, those SA participants willing to blend into the target culture may still take a longer than expected time to develop necessary skills and knowledge to fit into a new culture. For participants who are hesitant to do as the Chinese do, like Erkai, their agency may fluctuate with their experience in the target environment. They may learn certain things, but have more difficulty to overcome their presumption and the negative linguistic affordance from the SA environment. 


\section{Conclusion}

This study investigated by analyzing both quantitative and quality data what CR strategies four participants developed and how they developed the proficiency in an 8-week SA program in Shanghai, China. By unpacking the highly individualized CR developmental process each participant went through, the study uncovered how two salient influences: the linguistic affordance in the SA context and participants' agency intertwiningly shaped participants' CR development. The study findings illustrated that to fit into a target culture, learners need a strong commitment to being engaged in the dynamic and maybe quite slow-paced pragmatic developmental process which may include dealing with foreigner treatments, either over-hospitable or guarded, from native speakers in the target culture, particularly in a Chinese context where many people are not used to seeing and meeting foreigners. Hence, participation in a short-term study abroad program does not guarantee that learners can learn certain pragmatic skills to act like a Chinese. It is a rather complex process to be accepted and ready to do as the Chinese do.

Due to the case study approach adopted in this study, the findings should by no means be generalized to explain all pragmatic development processes that occur in a SA program. But it is hoped that the findings can shed light on the diversity and dynamics of pragmatic development, in this case, CR strategies, in a SA program in mainland China. There is not an outside-classroom learning protocol every learner should follow because each learner's background, prior experience with the target language and culture, current language proficiency, personality and even physical features may dialectically shape and be shaped by the people in the social cultural context, thus his/her personal experience in the target culture in a SA program. In other words, a SA environment is indeed "highly unpredictable and serendipitous" (Wilkinson 2005, p. 47). However, the unpredictable context does not prevent language educators and SA participants from getting prepared before embarking on the SA journal. To help SA participants get prepared for the compliment interactions particularly in the areas where native Chinese rarely meet exotic-looking foreigners, language educators could provide explicit CR instruction to alert how social cultural factors influence interactions in certain contexts. Participants' preliminary understanding of Chinese culture and its people may greatly influence how they behave and how well they are accepted by the local community, which may in turn affect whether and how they eventually adopt culturally appropriate CR strategies as the Chinese do.

Appropriate pragmatic skills enable a foreigner to verbally and non-verbally engage in social interactions with native speakers and possibly be better accepted in the target culture. SA participants' development of other pragmatic 
skills merits more research. This study only investigated four participants' development of CR strategies in a short-term SA program in China. Hence, the findings should not be generalized in all contexts. To have a better understanding of American students' language and culture learning in China, an increasingly popular SA site for American college students, larger-scale and longitudinal studies are needed to uncover the dynamic relationship between the complex social cultural contexts in China and American students' linguistic and cultural development during their SA sojourn.

\section{References}

Allen, Heather W. 2010. Language-learning Motivation in Short-term Study Abroad. Foreign Language Annals 43, 27-49.

Berg, Bruce L. 2004. Qualitative Research Methods for the Social Sciences. (5 $5^{\text {th }}$ Ed.). Boston, MA: Pearson.

Chen, Rong. 1993. Responding to compliments. A contrastive study of politeness strategies between American English and Chinese speakers. Journal of Pragmatics 20, 49-75.

Chen, Rong and Yang, Dafu. 2010. Responding to Compliments in Chinese: Has It Changed? Journal of Pragmatics 42, 1951-1963.

Engle, Lilli and Engle, John. 2004. Assessing Language Acquisition and Intercultural Sensitivity Development in Relation to Study Abroad Program Design. Frontiers: The Interdisciplinary Journal of Study Abroad 5, 219-236.

Fong, Mary. 1998. Chinese Immigrants' Perceptions of Semantic Dimensions of Direct/indirect Communication in Intercultural Compliment Interactions with North Americans. Howard Journal of Communication 9, 245-262.

Golato, Andrea. 2005. Compliments and Compliment Responses: Grammatical Structure and Sequential Organization. Amsterdam/Philadelphia: John Benjamins.

Herbert, Robert K. 1986. Say “Thank You” or Something. American Speech 61, 76-88. Herbert, Robert K. 1990. Sex-based Difference in Compliment Behavior. Language in Society 19, 201-224.

Hinkel, Eli. 1996. When in Rome: Evaluations of L2 Pragmalinguistic Behaviors. Journal of Pragmatics 26, 51-70.

Holmes, Janet. 1988. Compliments and Compliment Responses in New Zealand English. Anthropological Linguistics 28, 485-508.

lino, Masakazu. 2006. Norms of Interaction in a Japanese Homestay Setting: Toward Two-way Flow of Linguistic and Cultural Resources. In Margeret A. DuFon \& Eton Churchill (Eds.), Language Learners in Study Abroad Contexts, 151-173. Clevedon, UK: Multilingual Matters.

Institute of International Education. 2010. Open Doors 2010: Report on International Educational Exchange. New York, NY: IIE. Retrieved on December 1, 2010 from http://www.iie.org/en/Research-and-Publications/Open-Doors

Kádár, Dániel Z. and Pan, Yuling. 2011. Politeness in China. In Dániel Z. Kádár \& Sara Mills (Eds.), Politeness in East Asia, pp. 125-146. New York, NY: Cambridge University Press. 
Kasper, Gabriele. 2001. Four Perspectives on L2 Pragmatic Development. Applied Linguistics 22, 502-530.

Kasper, Gabriele and Richard Schmidt. 1996. Developmental Issues in Interlanguage Pragmatics. SSLA 18, 149-169.

Kinginger, Celeste. 2004. Alice Doesn't Live Here Anymore: Foreign Language Learning and Identity Reconstruction. In Aneta Pavlenko and Adrian Blackledge (Eds.), Negotiation of Identities in Multilingual Contexts, 219-242. Clevedon, UK: Multilingual Matters.

Kinginger, Celeste. 2009. Language Learning and Study Abroad. New York, NY: Palgrave Macmillan.

Kinginger, Celeste and Farrell, Kathleen. 2004. Assessing Development of Metapragmatic Awareness in Study Abroad. Frontiers: The Interdisciplinary Journal of Study Abroad 10: 19-42.

Lantolf, James P. and Pavlenko, Aneta. 2001. (S)econd (L)anguage (A)ctivity Theory: Understanding Second Language Learners as People. In Michael P. Breen (Ed.), Learner Contributions to Language Learning: New Directions in Research, 141-158. London: Longman.

Lantolf, James P., \& Thorne, Steven L. 2006. Sociocultural Theory and the Genesis of Second Language Development. Oxford, OX: Oxford University Press.

Lincoln, Yvonna S. and Guba, Egon G. 1985. Naturalistic Inquiry. New York: Sage.

Magnan, Sally S., \& Back, Michele. 2007. Social Interaction and Linguistic Gain during Study Abroad. Foreign Language Annals, 40, 43-61.

Miles, Matthew B. and Huberman, Michael. 1984. Qualitative Data Analysis: A Source Book for New Methods. Thousand Oaks, CA: Sage Publications.

Pan, Yuling. 2000. Politeness in Chinese Face-to-Face Interaction. Stamford, CT: Ablex Publishing Corporation.

Pavlenko, Alena and Lantolf, James P. 2000. Second Language Learning as Participation and the (Re)construction of Selves. In James P. Lantolf (Ed.), Sociocultural Theory and Second Language Learning, 155-177. Oxford: Oxford University Press.

Paige, R. Michael, Cohen, Andrew D., and Shively, Rachel. 2004. Assessing the Impact of a Strategies-based Curriculum on Language and Culture Learning Abroad. Frontiers: The Interdisciplinary Journal of Study Abroad, 10, pp. 253-276.

Pomerantz, Anita. 1984. Agreeing and Disagreeing with Assessments: Some Features of Preferred/Dispreferred Turn Shapes. In Maxwell-Atkinson, John and Heritage, John (Eds.), Structures of Social Action, 57-101. Cambridge: Cambridge University Press.

Siegal, Meryl. 1996. The Role of Learner Subjectivity in Second Language Sociolinguistic Competency: Western Women Learning Japanese. Applied Linguistics, 17, pp. 356-382.

Spencer-Oatey, Helen and Ng, Patrick. 2002. Reconsidering Chinese Modesty: Hong Kong and Mainland Chinese Evaluative Judgments of Compliment Responses. Journal of Asian Pacific Communication, 11 (2), pp. 181-201.

Stake, Robert. 1995. The Art of case study research. Thousand Oaks, CA: SAGE Publications, Inc.

Van Hoof, Hubert B. and Verbeeten, Marja J. 2005. Wine is for Drinking, Water is for Washing: Student Opinions about International Exchange Programs. Journal of Studies in International Education, 9(1), pp. 42-61.

van Lier, Leo. 2008. Agency in the Classroom. In James P. Lantolf and Matthew E. Poehner (Eds.), Sociocultural Theory and the Teaching of Second Languages, 163-186. London: Equinox. 
van Lier, Leo. 2004. The Ecology and Semiotics of Language Learning: A Sociocultural Perspective. Boston: Kluwer Academic Publishers.

van Lier, Leo. 2000. From Input to Affordance: Social-interactive Learning from an Ecological Perspective. In James P. Lantolf (Ed.), Sociocultural Theory and Second Language Learning, 245-259. Oxford: Oxford UP.

Vande Berg, Michael. 2004. Guest Editor. Special Issue on Study Abroad Research. Frontiers: The Interdisciplinary Journal of Study Abroad, 10, 253-276.

Vygotsky, Lev S. 1978. Mind in Society: The Development of Higher Psychologica Processes. Cambridge: Harvard University Press.

Wilkinson, Sharon. 2005. Articulating Study Abroad: The Depth Dimension. In Catherine M.

Barrette and Kate Paesani (Eds.), Language program articulation: Developing a theoretical foundation. Issues in language program direction: A series of annual volumes, 44-58). Boston: Heinle.

Wolfson, Nessa. 1983. An Empirically Based Analysis of Complimenting in English. In Nessa Wolfson \& Elliot Judd (Eds.), Sociolinguistics and Language Acquisition, 82-95. Rowley, MA: Newbury House.

Ye, Lei. 1995. Complimenting in Mandarin Chinese. In Gabriele Kasper (Ed.), Pragmatics of Chinese as Native and Target Language, 207-295. Honolulu, HA: University of Hawai'i, Second Language Teaching and Curriculum Center.

Yu, Ming-Chung. 2004. Interlinguistic Variation and Similarity in Second Language Speech Act Behavior. The Modern Language Journal, 88 (1), pp. 102-119.

\section{Appendix A}

Pre-study Survey

1. Your Age:

2. Your Gender:

3. Your current language level:

4. Your ethnicity:

5. Have you been exposed to Chinese language and culture including your language learning in a formal classroom setting? If yes, in what way?

6. Do you know how Chinese people respond to compliments? If so, write everything you know down. 
7. What is your purpose of participating in this study abroad program?

\section{Appendix B}

Interview Protocol for CR-related Scenarios

1. In the past one week, did you get any compliments from Chinese people? If yes, what compliment did you get? Who gave you the compliment? In what situation did you get the compliments such as when you passed a street vendor?

2. If you got compliments, did you respond? How did you respond? How did the Chinese react to your response? How do you feel about your response?

3. How often were you involved in a compliment-related conversation in the past week: none, 1 5, 6 10, 11 20, more than 20 ?

4. In the past week, did you overhear any compliment-related conversation between Chinese native speakers? If yes, what CR strategies did the native speakers use? Do you know why they used that?

5. Can you summarize what you learned about CR in China in the past week? 


\section{Appendix C}

\section{CR Strategies Matrix}

\begin{tabular}{|c|c|c|c|c|c|}
\hline & Week & Anli & Erkai & Siding & Diwen \\
\hline \multirow{4}{*}{2} & 哪里哪里 & $\begin{array}{l}\text { Chinese way to } \\
\text { respond } \vee\end{array}$ & Chinese way & $\begin{array}{l}\text { Chinese way to be } \\
\text { modest, more } \\
\text { polite } \mathrm{V} \text {, fit into } \\
\text { Chinese culture }\end{array}$ & $\begin{array}{l}\text { Most commonly } \\
\text { used by Chinese }\end{array}$ \\
\hline & 谢谢 & $\begin{array}{l}\text { Restaurant } \\
\text { manager used }\end{array}$ & American way $\mathrm{V}$ & American way & Westernized way \\
\hline & Other verbal & & & $\begin{array}{l}\text { 谢谢, 我的中文说 } \\
\text { 得不好 }\end{array}$ & $\begin{array}{l}\text { 哪里哪里, 我的 } \\
\text { 中文不好。 }\end{array}$ \\
\hline & Non-verbal & & $\begin{array}{l}\text { Chinese way: } \\
\text { Laugh or smile } \\
\text { shyly }\end{array}$ & & $\begin{array}{l}\text { Chinese looked } \\
\text { away }\end{array}$ \\
\hline \multirow{4}{*}{3} & 哪里哪里 & $\begin{array}{l}\text { Chinese way to } \\
\text { be modest }\end{array}$ & $\begin{array}{l}\text { Real compliment } \\
\text { on skills }\end{array}$ & Chinese way & Chinese way \\
\hline & 谢谢 & & American way & & $\begin{array}{l}\text { Westernized way } \\
\text { in Shanghai }\end{array}$ \\
\hline & Other verbal & $\begin{array}{l}\text { Less awkward } \\
\text { way: return the } \\
\text { compliment }\end{array}$ & & $\begin{array}{l}\text { 哪里哪里，你也很 } \\
\text { 漂亮。 }\end{array}$ & \\
\hline & Non-verbal & & laugh & & $\begin{array}{l}\text { Direct eyes away } \\
\text { Hand gesture } \\
\text { with a smile }\end{array}$ \\
\hline \multirow{4}{*}{4} & 哪里哪里 & & & Chinese way & Chinese way \\
\hline & 谢谢 & & & American way & Westernized way \\
\hline & Other verbal & & & & \\
\hline & Non-verbal & Brush it off & Laugh and nod & & smile \\
\hline
\end{tabular}




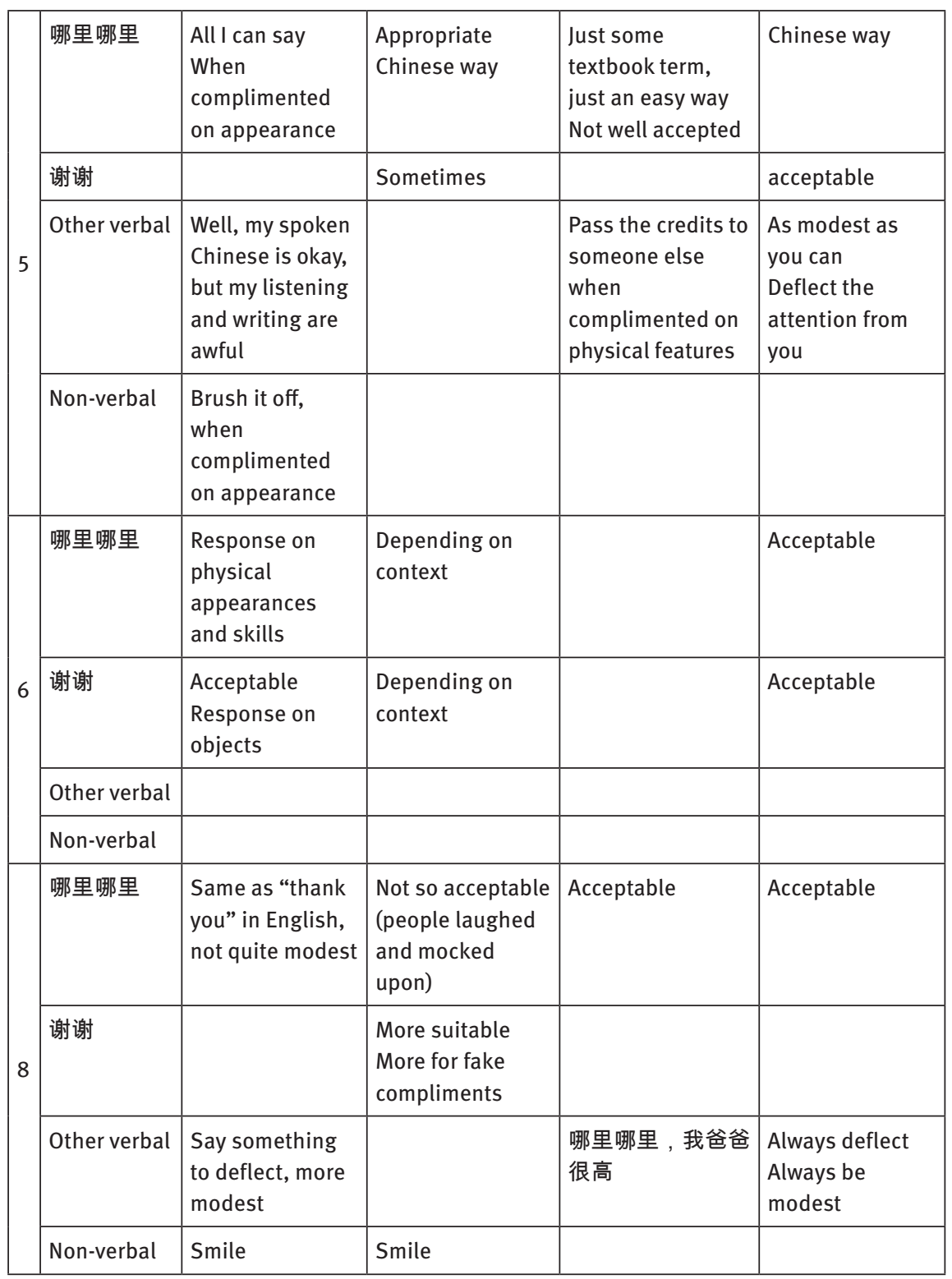




\section{Appendix D}

CR Development Matrix

\begin{tabular}{|c|c|c|c|c|c|}
\hline \multicolumn{2}{|r|}{ Week } & Anli & Erkai & Siding & Diwen \\
\hline \multirow{3}{*}{2} & $\begin{array}{l}\text { Frequency of } \\
\text { Compliment } \\
\text { Encounter }\end{array}$ & $10 \sim 20$ & $1 \sim 5$ & $10 \sim 20$ & $1 \sim 5$ \\
\hline & CR Interactant & $\begin{array}{l}\text { - street vendors; } \\
\text { - restaurant } \\
\text { workers; } \\
\text { - tourists; } \\
\text { - tutor }\end{array}$ & - tutor & $\begin{array}{l}\text { - street vendors; } \\
\text { - native residents } \\
\text { - tourists }\end{array}$ & $\begin{array}{l}\text { - street } \\
\text { vendors; } \\
\text { - cab drivers; }\end{array}$ \\
\hline & Learning venue & $\begin{array}{l}\text { - Chinese } \\
\text { reaction to } \\
\text { response; } \\
\text { - Chinese } \\
\text { response }\end{array}$ & $\begin{array}{l}- \text { Chinese } \\
\text { response }\end{array}$ & $\begin{array}{l}\text { - Chinese } \\
\text { reaction to } \\
\text { response }\end{array}$ & $\begin{array}{l}\text { - Chinese } \\
\text { response; } \\
\text { - Chinese } \\
\text { reaction to } \\
\text { response }\end{array}$ \\
\hline \multirow{3}{*}{3} & $\begin{array}{l}\text { Frequency of } \\
\text { Compliment } \\
\text { Encounter }\end{array}$ & $6 \sim 10$ & $1 \sim 5$ & $11 \sim 20$ & $1 \sim 5$ \\
\hline & CR Interactant & $\begin{array}{l}\text { - A veteran } \\
\text { American } \\
\text { learner in } \\
\text { China; } \\
\text { - class instructor }\end{array}$ & - tutor & $\begin{array}{l}\text { - tourists } \\
\text { - native residents }\end{array}$ & $\begin{array}{l}\text { - class } \\
\text { instructor; } \\
\text { - street vendors }\end{array}$ \\
\hline & Learning venue & $\begin{array}{l}\text { - advice } \\
\text { - Chinese } \\
\text { reaction to } \\
\text { response; }\end{array}$ & $\begin{array}{l}- \text { Chinese } \\
\text { response }\end{array}$ & $\begin{array}{l}\text { - Chinese } \\
\text { reaction to } \\
\text { response }\end{array}$ & $\begin{array}{l}\text { - Chinese } \\
\text { reaction to } \\
\text { response; } \\
\text { - Chinese } \\
\text { response }\end{array}$ \\
\hline
\end{tabular}




\begin{tabular}{|c|c|c|c|c|c|}
\hline \multirow{3}{*}{4} & $\begin{array}{l}\text { Frequency of } \\
\text { Compliment } \\
\text { Encounter }\end{array}$ & $6 \sim 10$ & $1 \sim 5$ & $1 \sim 5$ & $11 \sim 20$ \\
\hline & CR Interactant & - tutor & - a tea vendor & $\begin{array}{l}\text { - tutor } \\
\text { - tourists }\end{array}$ & $\begin{array}{l}\text { - street vendors } \\
\text { - cab drivers } \\
\text { - native } \\
\quad \text { residents }\end{array}$ \\
\hline & Learning venue & $\begin{array}{l}\text { - Chinese } \\
\text { reaction to the } \\
\text { response; }\end{array}$ & $\begin{array}{l}\text { - Chinese } \\
\text { response }\end{array}$ & $\begin{array}{l}\text { - Chinese } \\
\text { reaction to } \\
\text { responses }\end{array}$ & $\begin{array}{l}\text { - Chinese } \\
\text { reaction to } \\
\text { response; } \\
\text { - Chinese } \\
\text { response }\end{array}$ \\
\hline \multirow{3}{*}{5} & $\begin{array}{l}\text { Frequency of } \\
\text { Compliment } \\
\text { Encounter }\end{array}$ & $20 \sim$ & $1 \sim 5$ & $20 \sim$ & $11 \sim 20$ \\
\hline & CR Interactant & $\begin{array}{l}\text { - street vendors; } \\
\text { - restaurant } \\
\text { workers; } \\
\text { - tourists }\end{array}$ & $\begin{array}{l}\text { - masseuse } \\
\text { - street } \\
\text { vendors }\end{array}$ & $\begin{array}{l}\text { - native } \\
\text { residents; } \\
\text { - tourists }\end{array}$ & $\begin{array}{l}\text { - } \text { street } \\
\text { vendors; } \\
\text { - cab drivers; } \\
\text { - native } \\
\text { residents }\end{array}$ \\
\hline & Learning venue & 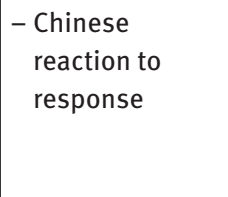 & $\begin{array}{l}\text { - Chinese } \\
\text { reaction to } \\
\text { response } \\
\text { - peers' } \\
\text { responses }\end{array}$ & $\begin{array}{l}\text { - Chinese } \\
\text { reaction to } \\
\text { response }\end{array}$ & $\begin{array}{l}\text { - Chinese } \\
\text { response; }\end{array}$ \\
\hline \multirow{3}{*}{6} & $\begin{array}{l}\text { Frequency of } \\
\text { Compliment } \\
\text { Encounter }\end{array}$ & $11 \sim 20$ & None & $11 \sim 20$ & $11 \sim 20$ \\
\hline & CR Interactant & $\begin{array}{l}\text { - tutor } \\
\text { - native } \\
\text { residents }\end{array}$ & None & $\begin{array}{l}\text { - native } \\
\text { residents; } \\
\text { - tourists }\end{array}$ & $\begin{array}{l}\text { - street vendors } \\
\text { - native } \\
\text { residents }\end{array}$ \\
\hline & Learning venue & $\begin{array}{l}\text { - Conversation } \\
\text { between } \\
\text { instructor and } \\
\text { peer } \\
\text { - Chinese } \\
\text { response }\end{array}$ & $\begin{array}{c}\text { - Discussion } \\
\text { with tutor }\end{array}$ & $\begin{array}{l}\text { - Chinese } \\
\text { reaction to } \\
\text { response; } \\
\text { - Chinese } \\
\text { response }\end{array}$ & $\begin{array}{l}\text { - Chinese } \\
\text { response; }\end{array}$ \\
\hline
\end{tabular}




\begin{tabular}{|c|c|c|c|c|c|}
\hline \multirow{3}{*}{8} & $\begin{array}{l}\text { Frequency of } \\
\text { Compliment } \\
\text { Encounter }\end{array}$ & $20 \sim$ & $6 \sim 10$ & $20 \sim$ & $20 \sim$ \\
\hline & CR Interactant & $\begin{array}{l}\text { - street vendors; } \\
\text { - tourists }\end{array}$ & $\begin{array}{l}\text { - street } \\
\text { vendors }\end{array}$ & $\begin{array}{l}\text { - street vendors } \\
\text { - tourists; } \\
\text { - native residents }\end{array}$ & $\begin{array}{l}\text { - street } \\
\text { vendors; } \\
\text { - native } \\
\text { residents }\end{array}$ \\
\hline & Learning venue & $\begin{array}{l}\text { - conversations } \\
\text { between native } \\
\text { Chinese; } \\
\text { - Chinese } \\
\text { reaction to } \\
\text { response; } \\
\text { - Chinese } \\
\text { response }\end{array}$ & $\begin{array}{l}\text { - Chinese } \\
\text { reaction to } \\
\text { response; }\end{array}$ & $\begin{array}{l}\text { - Chinese } \\
\text { reaction to } \\
\text { response; } \\
\text { - Chinese } \\
\text { response }\end{array}$ & $\begin{array}{l}\text { - Chinese } \\
\text { reaction to } \\
\text { response; } \\
\text { - Chinese } \\
\text { response }\end{array}$ \\
\hline
\end{tabular}

